\title{
DIGITALCOMMONS
}

@WAYNESTATE -

Wayne State University

Kinesiology, Health and Sport Studies

College of Education

1-1-1999

\section{Predictors of Social Physique Anxiety in Adolescent Swimmers With Physical Disabilities}

Jeffrey J. Martin

Wayne State University, aa3975@wayne.edu

\section{Recommended Citation}

Martin, J. J. (1999). Predictors of social physique anxiety in adolescent swimmers with physical disabilities. Adapted Physical Activity Quarterly, 16(1), 75-85.

Available at: http://digitalcommons.wayne.edu/coe_khs/7 


\title{
Predictors of Social Physique Anxiety in Adolescent Swimmers With Physical Disabilities
}

\author{
Jeffrey J. Martin \\ Wayne State University
}

\begin{abstract}
The purpose was to examine predictors of social physique anxiety (SPA) in adolescent swimmers with physical disabilities. Participants were 57 swimmers ( 27 females, 30 males, ages $16-19, M=16.2$ ) with various physical disabilities. A three-way ANOVA revealed significant differences in SPA between countries and among disabilities but not gender. Stepwise multiple regression results indicated that self-esteem and the self-identity subscale of the Athletic Identity Measurement Scale (AIMS) were the best predictors of SPA but that gender, country, and type of disability were not significant.
\end{abstract}

Self-presentation refers to the ways in which people manage how they present themselves to others (Goffman, 1959; Leary, 1992). Self-presentation theory suggests that individuals seek to enhance other people's favorable impressions about them and attempt to avoid unfavorable reactions (Leary, 1992). People who cannot effectively manage how others perceive them may experience social anxiety (Leary, 1983). In particular, social physique anxiety (SPA) is experienced when people anticipate or feel that their bodies are being devalued (Hart, Leary, \& Rejeski, 1989).

Eklund and Crawford (1994) and McAuley and Burman (1993) cited the need to examine self-referent based theoretical antecedents of SPA, such as body image and self-esteem, because social physique anxiety is thought to represent an affective outcome of these factors. To address this need, the current study was designed to examine two potential predictors of SPA in adolescent swimmers with physical disabilities: athletic identity and self-esteem.

SPA may be a particularly relevant psychological construct among adolescent swimmers with disabilities for three reasons. First, in sport and exercise the body is salient, important, and open to social evaluation (Hart, et al., 1989; Martens, Vealey, \& Burton, 1990). Thus, the social context of sport and exercise settings may promote SPA. Research on nondisabled exercisers and athletes suggests that SPA may influence sport and exercise behaviors. Crawford and Eklund (1994) found that college-age women with high SPA did not respond favorably to a video presentation of an exercise setting where aerobic dance clothing was worn. However,

Jeffrey J. Martin is with the Division of Health, Physical Education, and Recreation at Wayne State University, 266 Matthaei Bldg., Detroit, MI 48202. 
the same high-SPA women reacted positively when video participants were wearing attire that deemphasized the body. Additionally, Spink (1992) suggested that high-SPA women may exercise in private to avoid evaluative settings (e.g., exercise clubs) that may heighten SPA. Cumulatively, these initial findings suggest that exercise behavior (and by extension, sport behavior) may be influenced by SPA.

Second, physical appearance is a particularly important psychological construct associated with social acceptance among youth (Lerner et al., 1991). Adolescents with disabilities may be prone to high SPA because of personal expectations that their physical appearance will result in negative peer appraisal (Lerner \& Lerner, 1977; Pope, Fu, \& Warrell, 1981; Richardson, 1971; Sigelman, Miller, \& Whitworth, 1986).

Finally, Wallander and Varni's $(1992,1995)$ disability-stress-coping model of adjustment to chronic disabilities for adolescents emphasizes the importance of physical appearance. These researchers suggested that positive cognitive appraisal of physical appearance is an important coping factor for enhanced psychological adjustment. In contrast, negative appraisal of body image likely contributes to adjustment problems (Wallander \& Varni, 1995). In summary, adolescent swimmers with chronic and salient physical disabilities (e.g., cerebral palsy) may be at risk for SPA.

Although sport settings may exacerbate SPA, sport has also been promoted as a vehicle for developing positive social-psychological attributes (e.g., self-esteem) as well as improved physiological function (Sherrill, 1997, 1998). Additionally, sport is often advocated as a particularly important avenue for individuals with disabilities to accent their abilities and minimize disabilities (Sherrill, 1997, 1998). Sport may contribute to positive perceptions of the body through improved physical fitness and functional status. Improved functional capacity may help individuals view their bodies more positively and thus reduce negative body cognitions associated with surface qualities of the body (Blinde \& McClung, 1997). Thus, sport involvement, and more specifically psychological investment in sport, have the potential to help adolescent athletes with disabilities develop enhanced physical self-referent cognitions (Blinde \& McClung, 1997). McAuley and Burman's (1993) preliminary support for this premise with nondisabled persons indicated that physical self-efficacy and self-presentation confidence were negatively related to SPA. Female adolescent gymnasts with strong physical self-efficacy and self-presentation confidence were less likely to report SPA.

The present study focused on athletic identity as a predictor of SPA. Athletic identity refers to how much people identify with the athlete role (Brewer, Van Raalte, \& Linder, 1993). Recent research has shown that athletic identity is a relevant and important component of self-concepts among adolescent athletes with disabilities (Martin, Adams-Mushett, \& Eklund, 1994; Martin, Eklund, \& Mushett, 1997). Athletic identity was examined based on the premise that sport-related benefits (i.e., physical self-efficacy, enhanced body image) would be manifested most strongly in athletes whose self-concepts were strongly tied into the athlete role. This premise is rooted in social cognitive theory, which suggests that people value activities in which they are competent (Bandura, 1986).

In addition to athletic identity, researchers have indicated that self-esteem is related to body-esteem, or how well an individual likes his or her body (Fox, 1997; Harter, 1993; Lerner, Karabenick, \& Stuart, 1973; Rosen \& Ross, 1968). Positive relationships between body- and self-esteem in nondisabled adolescent girls (Folk, 
Pedersen, \& Cullari, 1993; Kenealy, Gleeson, Frude, \& Shaw, 1991) and college students (Secord \& Jourard, 1953) indicate that individuals who are pleased with their bodies are likely to have higher self-esteem compared to people who are less satisfied with their physical selves.

Based on these results, we would expect that individuals with low self-esteem are prone to SPA. In fact, findings from one study suggest that self-esteem may be a better predictor of SPA than more specific, body-related cognitions, such as bodyesteem (Martin, Engels, Wirth, \& Smith, 1997).

To summarize, the primary purpose of this study was to examine SPA predictors in adolescent swimmers with disabilities. Results of this study may further our understanding of SPA in individuals with physical disabilities as well as lead to implications for teachers and coaches. As Crocker (1993) and Reid (1989) suggested, examining theory-based research, such as self-presentation and self-concept theories, on individuals with disabilities helps extend and refine theories under investigation. In addition, informing teachers and coaches about SPA predictors may heighten their awareness of how sport (i.e., swimming) can help individuals with disabilities in developing positive self-perceptions (i.e., self-esteem) and i 2 ducing negative affect (i.e., SPA).

\section{Method}

\section{Participants}

Participants were 57 adolescent swimmers (27 females and 30 males) with disabilities (cerebral palsy, $n=24$, amputee, $n=13$, paraplegic, $n=13$, and Les Autres [Others], $n=7$ ) competing at the Rotary International Junior Swimming Match in Glasgow, Scotland. Les Autres $(n=7)$ included swimmers classified as dwarfs, those with osteomyelitis, and others. Swimmers (ages 16-19, $M=16.2$ ) represented their national teams (England, $n=9$, Ireland, $n=15$, Scotland, $n=19$, United States, $n=12$, and Wales, $n=2)$ at this international competition. For purposes of this study, the United Kingdom (U.K.; $n=45$ ) and United States (U.S.; $n=12$ ) were the comparison groups.

\section{Instruments}

Social Physique Anxiety Scale (SPAS). Hart et al.'s (1989) SPAS assesses people's anxiety due to perceptions that their bodies are or might be devalued by others. Participants used a 5-point Likert scale and responded to 12 items. Scores ranged from 12 to 60 , with higher scores indicating greater SPA. The following is an example of one item: "In the presence of others, I feel apprehensive about my physique/figure."

One alteration was made to the instrument for the present study. Item 2 ("I would never worry about wearing clothes that might make me look too thin or overweight"), which is negatively worded, was modified to the following positive statement: "I would worry about wearing clothes that might make me look too thin or overweight." This change was based on the recommendation of numerous researchers (Crawford \& Eklund, 1994; Eklund, Mack, \& Hart, 1996; McAuley \& Burman, 1993), who found that the negative wording led to participant confusion and low item-to-total correlations. 
Although researchers (e.g., Cramer-Hammann, Lutter, Cornelius, Piontek, $\&$ Hardy, 1993) have questioned the unidimensionality of the SPAS, a recent factorial validity study of 760 females (ages 13-35) without disabilities suggested that a model with two first-order factors subordinate to one is best (Eklund, Mack, \& Hart, 1996). Additional research using confirmatory factor analyses also indicated that one factor is most appropriate (Martin, Rejeski, Leary, McAuley, \& Bane, 1992). Thus, I analyzed only the total SPA score. Adequate internal consistency $(r=.90)$, predictive validity, and construct validity have been documented for female nondisabled athletes and exercisers who complete the SPAS (Crawford \& Eklund, 1994; Hart et al., 1989; McAuley \& Burman, 1993). Based on the current sample, the alpha reliability coefficient for the SPAS was .87.

Athletic Identity Measurement Scale (AIMS). The 9-item AIMS, developed by Brewer et al. (1993) to assess athletic identity, contains four subscales: selfidentity, social identity, exclusivity, and negative affectivity (Martin et al., 1994). For each item, participants respond on a 7 -point scale $(7=$ strongly agree and $1=$ strongly disagree). Scores range from 2 to 14 for the two-item social identity (Items 3 and 7), self-identity (Items 1 and 2), and negative affectivity subscales (Items 8 and 10). Scores range from 3 to 21 for the three-item exclusivity subscale (Items 4 , 5, and 9). Social identity (SO) indicates how strongly athletes identify with the athletic role. Self-identity (SE) refers to self-referenced cognitions in contrast to social identity, which reflects athletes' perceptions of how others view them. Exclusivity $(\mathrm{EX})$ is the degree to which athletes rely exclusively on their athletic identities. Negative affectivity (NA) assesses negative emotional responses resulting from the inability to participate in sport. The AIMS has been shown to produce reliable and valid scores. The test-retest for the total AIMS score (.89), reliability, internal consistency (.80-.93), construct validity via factor analysis, and concurrent validity have been examined for AIMS among adolescent athletes with (Martin, Adams-Mushett, \& Eklund, 1994; Martin, Eklund, \& Mushett, 1997) and without disabilities (Brewer et al., 1993).

Self-Esteem (SELF). Rosenberg's (1965) self-esteem inventory is a 10-item scale with scores ranging from 1 (strongly disagree) to 4 (strongly agree). Total scores range from 10 to 40, with higher scores indicating more favorable self-esteem. The following is an example item: "On the whole, I am satisfied with myself."

Adequate internal consistency $(r=.92)$, test-retest reliability $(r=.85)$, and convergent and discriminant validity have been demonstrated for individuals without disabilities (Wylie, 1974). Researchers using Rosenberg's (1965) self-esteem inventory to examine athletes with disabilities suggests that it is a psychometrically sound instrument for assessing self-esteem in this population (Campbell, 1995; Campbell \& Jones, 1994; Hopper, 1986).

\section{Procedure}

Research packets, which were distributed to participants the night before the 2 day competition, contained the following: a letter describing the study, a consent form, a demographic questionnaire (e.g., age, gender, team affiliation, event), and the SPAS, AIMS, and self-esteem scales.

Athletes, who received standardized verbal instructions, were assisted by the researchers or team support staff if their disabilities prevented them from independently completing the instruments. Data for this study were part of a larger data set, and AIMS data have been published elsewhere (Martin, Adams-Mushett, \& Smith, 1995). 


\section{Results}

\section{Reliability of Measures}

Alpha reliability coefficients for the SPA (.87), self-esteem (.80), and the AIMS subscales $(.64, .65, .72, .72)$ indicated adequate internal consistency among the instruments (Cronbach, 1951; Nunnally, 1978).

\section{Gender, Disability, and Country Differences}

A three-way ANOVA was conducted to determine if SPA differences based on gender, disability, or country would affect the statistical design of the study (i.e., whether genders could be combined in subsequent analyses). Results indicated an overall main effect, $F(5,41)=3.78, p<.01$, two significant main effects, and no significant interactions. The first significant main effect, $F(1,41)=5.70, p<.05$, eta squared $=.37$, was for country; swimmers from the U.K. had higher SPA $(M=$ 33.07) than those from the U.S. $(M=26.75)$. The second significant main effect, $F(3,41)=3.28, p<.05$, eta squared $=.31$, for disability group required a post-hoc test to locate the significant differences among the four disability groups. I used Scheffé's test - a conservative one - to limit the probability of committing a Type 1 error (Cramer, 1994). Results, $F(3,53)=2.78, p<.05$, indicated that Les Autres had higher SPA $(M=38.86)$ than the amputees $(M=27.92)$. There were no significant main effects for gender.

Effect sizes (eta squared) were reported for the two significant main effects as recommended by Sutlive and Ulrich (1998). Based on Cohen's (1988) guidelines, effect sizes that account for over $15 \%$ of variance are considered large. Thus, .37 and .31 indicate substantial differences among the means tested.

ANOVA findings supported combining genders but not countries or disability groups in subsequent statistical analyses. Significant main effects for country and disability (see Table 1) indicated that overall results for this study cannot be generalized across these factors. This result affects all data interpretation. For example, the mean SPA of 31.8 reported in Table 1 does not represent that for the U.K. $(M=33.6)$ or U.S. $(M=26.8)$. In addition, the mean SPA of 31.8 in Table 1 does not reflect the diversity of the disability groups: cerebral palsy, $M=31.7$, paraplegic, $M=31.8$, amputee, $M=27.9$, and Others, $M=38.9$.

\section{Descriptive Results}

As Table 1 indicates, participants experienced some SPA $(M=31.8)$. Based on Hart et al.'s (1989) SPAS headers, swimmers reported experiencing SPA slightly to moderately. Swimmers' self-esteem scores were positive; their mean score $(M=$ 31.9) suggests that they agreed with positive self-evaluative statements. Finally, based on the AIMS total score $(M=41.2)$, participants viewed themselves as athletes.

\section{Correlation and Regression Results}

Table 2 indicates that 7 of 15 correlations among SPA, self-esteem, and the AIMS subscales were significant. SPA was significantly and negatively related to selfesteem $(r=-.54)$ and the AIMS self-identity subscale $(r=-.47)$. Because self-esteem and self-identity were the only two scales significantly correlated with SPA, they were entered into a stepwise regression analysis (SPSS-X, 
Table 1 Performance of 57 Swimmers (27 Females and 30 Males) on Social Physique Anxiety, Self-Esteem, and Athletic Identity Measurement Subscales

\begin{tabular}{lrrrr}
\hline & & & \multicolumn{2}{c}{ Range } \\
& $M$ & $S D$ & Participants & Scale \\
\hline SPA & 31.8 & 8.6 & $13-54$ & $12-60$ \\
SELF & 31.9 & 4.3 & $21-40$ & $10-40$ \\
SE & 11.9 & 2.3 & $4-14$ & $2-14$ \\
SO & 8.5 & 3.9 & $2-14$ & $2-14$ \\
EX & 10.6 & 4.9 & $3-20$ & $3-21$ \\
NE & 10.1 & 3.5 & $2-14$ & $2-14$ \\
AIMS & 41.2 & 11.8 & $16-63$ & $9-63$ \\
& & & & \\
\hline
\end{tabular}

Note . SPA = Social physique anxiety; $\mathrm{SELF}=$ Self-esteem; $\mathrm{SE}=$ Self-identity $; \mathrm{SO}=$ Social identity; EX = Exclusivity; NE = Negative affectivity; AIMS = Total score for the Athletic Identity Measurement Scale.

Table 2 Pearson Product Moment Correlations Among Social Physique Anxiety, Self-Esteem, and Athletic Identity Subscales

\begin{tabular}{lccccc}
\hline & SELF & SE & SO & EX & NE \\
\hline SPA & $-.54^{* *}$ & $-.47^{* *}$ & -.25 & -.16 & -.03 \\
SELF & & $.47^{* *}$ & .03 & -.22 & -.20 \\
SE & & & $.46^{* *}$ & $-.26^{*}$ & .25 \\
SO & & & & $.43^{* *}$ & .18 \\
EX & & & & $.43^{* *}$ \\
\hline
\end{tabular}

Note. SPA = Social physique anxiety; SELF = Self-esteem; SE = Self-identity; $\mathrm{SO}=$ Social identity; $\mathrm{EX}=$ Exclusivity; $\mathrm{NE}=$ Negative affectivity .

${ }^{*} p<.05$. ** $p<.01$.

1988) to determine SPA predictors. Additionally, country (U.S. and U.K.) and disability were entered into the regression equation using dummy coding because of SPA differences. Table 3 reports results of the stepwise regression analyses, which indicate that a combination of self-esteem and AIMS self-identity predicted $36 \%$ of SPA variance. Country and disability type were not entered into the regression equation.

\section{Discussion}

The major purpose of this study was to examine SPA predictors among adolescent swimmers with physical disabilities. To my knowledge, the current study is the 
Table 3 Stepwise Regression Analysis of SPA Predictors

\begin{tabular}{llccc}
\hline & & \multicolumn{3}{c}{ Prediction of SPA } \\
\cline { 3 - 5 } & Beta & $R^{2}$ & Adjusted $R^{2}$ & $R^{2}$ change \\
\hline $\begin{array}{l}\text { Stepwise entry } \\
\text { Step 1 } \\
\text { SELF }\end{array}$ & & & & \\
Step 2 & $-.40^{* *}$ & .29 & .28 & - \\
AIMS: SE & $-.30^{*}$ & .36 & .34 & .07 \\
\hline
\end{tabular}

Note. SELF = Self-esteem; AIMS: SE = Self-identity subscale of the Athletic Identity Measurement Scale.

$* p<.05 . * * p<.01$.

first research effort to examine SPA in athletes in this population. The rationale for the study emphasized that swimmers with disabilities may be at special risk for SPA because of the saliency and importance of body image in sport in particular and society in general. Descriptive results indicated that adolescent swimmers with disabilities have relatively slight to moderate levels of SPA. Swimmers with disabilities had a mean SPA of $31.8(S D=8.6)$ compared to a mean of $37.3(S D=9.8)$ for 94 nondisabled undergraduate physical education class participants (Crawford \& Eklund, 1994) and a mean of $29.3(S D=8.8)$ for 68 nondisabled elite female youth athletes (Martin, Engels, Wirth, \& Smith, 1997). Although Les Autres reported higher SPA compared to swimmers with amputations, their levels were still in the moderate range $(M=38.9)$. Furthermore, the small number (e.g., $n=7)$ of athletes with varied, other disabilities warrants viewing these results with caution.

Adolescent swimmers' self-esteem $(M=31.9)$ was similar to the reported mean (29.3) for 68 elite able-bodied female youth gymnasts, soccer players, and skaters (Martin et al., 1997). In contrast, Campbell (1995) reported 21.5 for adult wheelchair athletes in the United Kingdom.

These results suggest that adolescent swimmers with disabilities do not experience excessively high levels of SPA or possess low self-esteem compared to other disability and nondisabled athletic and exercise groups (Campbell, 1995; Crawford \& Eklund, 1994; Eklund \& Crawford, 1994; McAuley \& Burman, 1993; Martin et al., 1997). This finding was somewhat unexpected. Adolescents with disabilities may be prone to high SPA because of the expectation or perception of negative peer appraisal of their physical selves.

However, Rosenberg's (1979) explanation for racial and ethnic minority groups can be generalized to disability groups, who are often defined as minorities (Kahn, 1984). Rosenberg (1979) suggested that it is erroneous to assume that the negative views of the majority (i.e., nondisability groups) about the minority (i.e., disability groups) result in low self-regard, because minority group members may not be aware of or agree with these views. Furthermore, minority groups may deem the majority groups' attitudes as irrelevant and insignificant. Finally, 
Rosenberg indicated that minority groups' standards of reference for making social comparisons are typically based on their own minority group's values, and not those of the majority. Athletes in this sample may not have reported high SPA and low self-esteem because they were not comparing their bodies to nondisabled individuals, accepting nondisabled bodies as the norm, and judging their bodies as inferior.

Furthermore, sport participation may help adolescents recognize the body's functionality while helping them diminish body image concerns (Blinde \& McClung, 1997). Sherrill, Hinson, Gench, Kennedy, and Low (1990) reported that adolescent athletes with physical disabilities $(N=158)$ had mean self-concept scores on the Harter (1988) instrument that were within or close to ranges in the test manual for nondisabled adolescents. Sherrill et al. (1990) posited that these findings might reflect deep-seated denial mechanisms or pride in their fitness and appearance compared to nonathletes with disabilities. This latter reason supports Rosenberg's (1979) social comparison explanation.

The significant main effects for disability and country in this study emphasize the importance of not stereotyping all persons with disabilities as having the same attributes. SPA differences between Les Autres and the amputee group especially indicate that SPA may be related to disability condition and severity. The significant difference in SPA between U.S. and U.K. athletes might be the result of sociocultural factors pertaining to sport socialization and participation as well as the dominant model (medical vs. nonmedical) in disability social and educational services. Although body image research suggests that White women are more likely to desire a thinner body compared to Asian, African, or African-American females (Davis, 1997), researchers have not yet examined ethnic or country differences in SPA among people with disabilities.

Because disability and country did not enter in the regression equation, psychological constructs (e. g., self-esteem and athletic identity), which are partially products of sociocultural influence (Brewer et al., 1993; Rosenberg, 1979), may have more predictive power than disability and country. Future research on gender, disability type, culture, and SPA relationships is warranted.

Correlation results indicated that athletes with strong AIMS self-identities and favorable self-esteem were less likely to report SPA compared to athletes with less confidence in these areas. Furthermore, the positive contributions of possessing a strong AIMS self-identity and self-esteem are somewhat independent $(r=$ .47 ) and share less than $25 \%$ variance. This independence likely accounts for their unique contributions to predicting SPA in the regression equation. Together, they accounted for $36 \%$ of SPA variance, with self-esteem contributing $29 \%$. Future research on specific self-presentational concerns related to body image (as well as self-esteem and AIMS self-identity) may help explain variance unaccounted for in SPA.

According to Harter (1993), the consistent and strong $(r=.70-.80)$ positive relationship between physical appearance and self-esteem is the result of body image cognitions becoming tightly interwoven into a person's self-esteem. The body is constantly on display and salient and invites evaluative reactions from others as early as infancy (Harter, 1993). Thus, both positive and negative body image cognitions become incorporated into self-esteem, which is thus strongly related to constructs such as SPA, which are partially dependent on body image. Research with nondisabled athletes has also shown that self-esteem is more strongly predictive of SPA than more specific body-related cognitions (Martin et al., 1997). 
Athletes invested in sport, as assessed by athletic identity, may develop enhanced physical self-efficacy and self-presentation confidence, which lead to reduced SPA, compared to athletes with less strength in these areas (McAuley \& Burman, 1993). Sport-specific cognitions, such as self-presentation confidence and physical self-efficacy, may mediate the relationship between athletic identity and SPA. Future research should ascertain the veracity of this suggestion.

In conclusion, self-esteem and AIMS self-identity are the best predictors of SPA among adolescent swimmers with physical disabilities. The relatively small and unique sample in this investigation limits generalizing these findings to other athletic groups. However, the present study provides preliminary evidence suggesting the need for continued research.

\section{References}

Bandura, A. (1986). Social foundations of thought and action. Englewood Cliffs, NJ: Prentice Hall.

Blinde, E.M., \& McClung, L.R. (1997). Enhancing the physical and social self through recreational activity: Accounts of individuals with physical disabilities. Adapted Physical Activity Journal, 14, 327-344.

Brewer, B.W., Van Raalte, J.L., \& Linder, D.E. (1993). Athletic identity: Hercules' muscles or Achilles heel? International Journal of Sport Psychology, 24, 237-254.

Campbell, E. (1995). Psychological well-being of participants in wheelchair sports: Comparison of individuals with congenital and acquired disabilities. Perceptual and $\mathrm{Mo}$ tor Skills, 81, 563-568.

Campbell, E., \& Jones, G. (1994). Psychological well-being in wheelchair sport participants and nonparticipants. Adapted Physical Activity Journal, 11, 404-415.

Cohen, J. (1988). Statistical analysis for the behavioral sciences (2nd ed.). Hillsdale, NJ: Lawrence Erlbaum.

Cramer, D. (1994). Introducing statistics for social research. New York: Routledge.

Cramer-Hammann, B., Lutter, C., Cornelius, A., Piontek, K., \& Hardy, C.J. (1993, September). Understanding the factor structure of the social physique anxiety scale. Presented at the annual meeting of the Association for the Advancement of Applied Sport Psychology, Montreal, PQ, Canada.

Crawford, S., \& Eklund, R.C. (1994). Social physique anxiety, reasons for exercise, and attitudes towards exercise settings. Journal of Sport and Exercise Psychology, 16, 70-82.

Crocker, P.R.E. (1993). Sport and exercise psychology and research with athletes with physical disabilities: Using theory to advance knowledge. Adapted Physical Activity Journal, 10, 324-335.

Cronbach, L.J. (1951). Coefficient alpha and the internal structure of tests. Psychometrika, 16, 297-334.

Davis, C. (1997). Body image, exercise, and eating behaviors. In K.R. Fox (Ed.), The physical self: From motivation to well-being (pp. 143-174). Champaign IL: Human Kinetics.

Eklund, R.C., \& Crawford, S. (1994). Active women, social physique anxiety, and exercise. Journal of Sport and Exercise Psychology, 16, 431-448.

Eklund, R.C., Mack, D., \& Hart, E. (1996). Factorial validity of the Social Physique Anxiety Scale for females. Journal of Sport and Exercise Psychology, 18, 281-295.

Folk, L., Pedersen, J., \& Cullari, S. (1993). Body satisfaction and self-concept of third- and sixth-grade students. Perceptual and Motor Skills, 76, 547-553. 
Fox, K. (1997). The physical self: From motivation to well-being. Champaign, IL: Human Kinetics.

Goffman, E. (1959). The presentation of self in everyday life. New York: Doubleday.

Hart, E.A., Leary, M.R., \& Rejeski, W.J. (1989). The measurement of social physique anxiety. Journal of Sport and Exercise Psychology, 11, 94-104.

Harter, S. (1988). Manual for the Self-Perception Profile for Adolescents. Denver, CO: Author.

Harter, S. (1993). Causes and consequences of low self-esteem in children and adolescents. In R.F. Baumeister (Ed.), Self-esteem: The puzzle of low self-regard (pp. 87-116). New York: Plenum.

Hopper, C. (1986). Socialization of wheelchair athletes. In C. Sherrill. (Ed.), Sport and disabled athletes (pp. 197-202). Champaign, IL: Human Kinetics.

Isogai, H. (1995, June 16). Gender differences in social physique anxiety. Paper presented at the annual meeting of the North American Society for the Psychology of Sport and Physical Activity, Pacific Grove, CA.

Kahn, A.S. (1984). Perspectives on persons with disabilities. American Psychologist, 39, 516-517.

Kenealy, P., Gleeson, K., Frude, N., \& Shaw, W. (1991). The importance of the individual in the "causal" relationship between attractiveness and self-esteem. Journal of Community and Applied Social Psychology, 1, 45-56.

Leary, M.R. (1983). Understanding social anxiety. Beverly Hills, CA: Sage.

Leary, M.R. (1992). Self-presentational processes in exercise and sport. Journal of Sport and Exercise, 14, 339-351.

Lerner, R.M., Karabenick, S.A., \& Stuart, J.L. (1973). Relations among physical attractiveness, body attitudes, and self-concept in male and female college students. Journal of Psychology, 85, 119-129.

Lerner, R.M., \& Lerner, J.V. (1977). Effects of age, sex, and physical attractiveness on child-peer relations, academic performance, and elementary school adjustment. $D e$ velopmental Psychology, 13, 585-590.

Lerner, R.M., Lerner, J.V., Hess, L.E., Schwab, J., Jovanovic, J., Talwar, R., \& Kucher, J.S. (1991). Physical attractiveness and psychosocial functioning among early adolescents. Journal of Early Adolescence, 11, 300-320.

Martens, R., Vealey, R.S., \& Burton, D.(1990). Competitive anxiety in sport. Champaign, IL: Human Kinetics.

Martin, J.J., Adams-Mushett, C., \& Eklund, R. (1994). Factor structure of the Athletic Identity Measurement Scale with adolescent swimmers with disabilities. Brazilian Journal of Adapted Physical Education Research, 1, 87-100.

Martin, J.J., Adams-Mushett, C., \& Smith, K.L. (1995). Athletic identity and sport orientation of adolescent swimmers with disabilities. Adapted Physical Activity Journal, 12, 113-123.

Martin, J.J., Eklund, R., \& Mushett, C. (1997). Factor structure of the Athletic Identity Measurement Scale with athletes with disabilities. Adapted Physical Activity Journal, 14, 74-82.

Martin, J.J., Engels, H.J., Wirth, J., \& Smith, K.L. (1997). Predictors of social physique anxiety in elite youth female athletes. Women in Sport and Physical Activity Journal, 6, 29-48.

Martin, K.A., Rejeski, W.J., Leary, M.R., McAuley, E., \& Bane, S. (1992). Is social physique anxiety scale really multidimensional? Conceptual and statistical arguments for a undimensional model. Journal of Sport and Exercise, 19, 359-367. 
McAuley, E., \& Burman, G. (1993). The Social Physique Anxiety Scale: Construct validity in adolescent females. Medicine and Science in Sport and Exercise, 25, 1049-1053.

Nunnally, J.C. (1978). Psychometric theory (2nd ed.). New York: McGraw Hill.

Pope, R.A., Fu, V.R., \& Warrell, S.E. (1981). Preschool children's recognition and acceptance of three physical disabilities. Child Study Journal, 11, 99-114.

Reid, G. (1989). Ideas about motor behavior research with special populations. Adapted Physical Activity Journal, 6, 1-10.

Richardson, S.A. (1971). Children's values and friendships: A study of physical disability. Journal of Health and Social Behavior, 12, 253-258.

Rosen, G.M., \& Ross, A.O. (1968). Relationship of body image to self-concept. Journal of Consulting and Clinical Psychology, 32, 1.

Rosenberg, M. (1965). Society and the adolescent self-image. Princeton, NJ: Princeton University Press.

Rosenberg, M. (1979). Conceiving the self. New York: Basic Books.

Secord, P., \& Jourard, S. (1953). The appraisal of body-cathexis: Body-cathexis and the self. Journal of Consulting Psychology, 17, 343-347.

Sherrill, C. (1997). Disability, identity, and involvement in sport and exercise. In K.R. Fox (Ed.). The physical self: From motivation to well-being (pp. 257-286). Champaign IL: Human Kinetics.

Sherrill, C. (1998). Adapted physical activity, recreation and sport: Crossdisciplinary and lifespan (5th ed.). Madison, WI: WCB/McGraw Hill.

Sherrill, C., Hinson, M., Gench, B., Kennedy, S., and Low, L. (1990). Self-concepts of disabled youth athletes. Perceptual and Motor Skills, 70, 1093-1098.

Sigelman, C.K., Miller, T.E., \& Whitworth, L.A. (1986). The early development of stigmatizing reactions to physical differences. Journal of Applied Developmental Psychology, 7, 17-32.

Spink, K.S. (1992). Relation of anxiety about social physique to location of participation in physical activity. Perceptual and Motor Skills, 74, 1075-1078.

SPSS-X. Advanced User's Guide (2nd ed.). (1988). Chicago: SPSS.

Sutlive, V.H., \& Ulrich, D.A. (1998). Interpreting statistical significance and meaningfulness in adapted physical activity research. Adapted Physical Activity Journal, 15, 103-118.

Wallander, J.L., \& Varni, J.W. (1992). Adjustment in children with chronic physical disorders: Programmatic research on a disability-stress-coping model. In A.M. LaGreca, L.J. Siegel, J.L. Wallander, \& C.E. Walker (Eds.), Advances in pediatric psychology: Stress and coping in child health (pp. 279-297). New York: Guilford Press.

Wallander, J.L., \& Varni, J.W. (1995). Appraisal, coping, and adjustment in adolescents with a physical disability. In J.L. Wallander \& L.J. Siegel (Eds.), Adolescent health problems: Behavioral perspectives (pp. 209-229). New York: Guilford Press.

Wylie, R.C. (1974). The self-concept. Vol. 1: A review of methodological and measuring instruments (2nd ed.). Lincoln: University of Nebraska Press.

\section{Author Note}

I would like to thank Dr. Claudine Sherrill and two anonymous reviewers for their valuable comments and suggestions throughout the review process. 